\title{
Iron for Florida Turfgrasses ${ }^{1}$
}

\author{
T. W. Shaddox and J. B. Unruh²
}

Iron $(\mathrm{Fe})$ is commonly applied using granular or foliar sources to enhance turfgrass color. Iron applications can result in darker green turfgrass but may result in no turfgrass response at all. Understanding the dynamics of Fe both in the plant and in the soil could greatly enhance your nutrient management programs. The objective of this publication is to explain the function of Fe within the plant, describe the Fe sources available for turfgrasses, and identify which forms (i.e., sources) of Fe are most effective in improving turfgrass quality.

\section{Function of Iron in Turfgrasses}

Turfgrass can appear darker green after an Fe application because the supply of Fe from the soil is low and the demand for $\mathrm{Fe}$ in the plant is high. Iron is needed in numerous photosynthetic functions, including activation of enzymes that catalyze chlorophyll synthesis, maintenance of thylakoid membrane (the site of the light-dependent photosynthesis reactions) structural integrity, and the transfer of electrons during photosynthesis (Salisbury and Ross 1992). Although several nutritional elements may result in darker green turfgrass, the roles of most elements within the plant are not interchangeable with one another. For example, the application of Fe will not cure nitrogen (N) deficiency.

Iron is immobile in the plant (i.e., does not move from one plant tissue to another) and, thus, deficiency appears on younger leaves first. Iron deficiency is commonly observed in Florida in the spring following $\mathrm{N}$ fertilizer applications, especially to bahiagrass, centipedegrass, and St. Augustinegrass. This can be frustrating because the $\mathrm{N}$ application should have resulted in greener turfgrass, but, in fact, the lawn may appear chlorotic in places. The most likely explanation is that during the winter months, the rate of turfgrass shoot and root growth declines. In north Florida, growth may cease altogether, whereas in south Florida, growth may slow down. Nitrogen applied during the spring encourages turfgrass growth and, in turn, increases the demand for Fe. This demand for Fe cannot be met because turfgrass root growth is still limited in the spring and, thus, the ability to take up Fe is low, resulting in chlorotic leaf blades. Cool, wet soils tend to exacerbate this chlorosis. As soil temperatures increase, the quantity of turfgrass roots increases, resulting in greater uptake of Fe and a decrease in Fe deficiency symptoms. Springtime occurrences of Fe deficiency normally dissipate within a few weeks. Otherwise, turfgrass Fe chlorosis can be minimized by applying foliar Fe (liquid Fe applied to the leaves) at a rate between 1-5 lbs of Fe per acre (Figure 1).

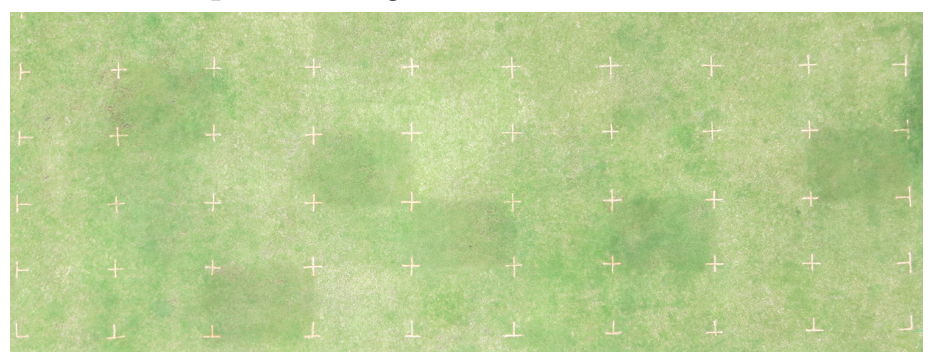

Figure 1. Bermudagrass showing response to foliar iron (each dark green rectangle) compared to granular Fe or no Fe (all remaining rectangles).

Credits: Travis Shaddox, UF/IFAS

1. This document is ENH1287, one of a series of the Environmental Horticulture Department, UF/IFAS Extension. Original publication date January 2018. Visit the EDIS website at http://edis.ifas.ufl.edu.

2. T. W. Shaddox, assistant professor, UF/IFAS Ft. Lauderdale Research and Education Center, Davie, FL 33314; and J. B. Unruh, professor and associate center director, Department of Environmental Horticulture, UF/IFAS West Florida Research and Education Center, Jay, FL 32565. 


\section{Soil Iron}

Iron makes up about $5 \%$ of the earth's crust, but most of this $\mathrm{Fe}$ is unavailable for plant uptake because it is bound in primary or secondary minerals such as goethite and hematite (Havlin et al. 1999). Compared with other cations in the soil solution, soluble Fe is usually very low and is commonly lower than necessary to meet plant requirements. So how does turfgrass acquire $\mathrm{Fe}$ if the soluble Fe is insufficient? Turfgrass exudes natural chelating compounds known as phytosiderophores that complex Fe and render the Fe available for plant uptake (Carrow et al. 2001). Even with the ability to chelate soil Fe, turfgrasses may not receive sufficient $\mathrm{Fe}$ to achieve the desired green color expected by many turf managers or homeowners. In these cases, Fe fertilizers can be used to enhance turfgrass greening.

The availability of Fe in soils is dependent upon soil moisture, soil $\mathrm{pH}$, soil temperature, and organic matter content. As soil moisture increases, the quantity of Fe available for plant uptake also increases, because the rate of Fe oxidation is much lower when oxygen is limited. This may seem advantageous, but limited oxygen also negatively influences turfgrass root growth. Thus, a moist soil that is not too dry or too wet is ideal. Iron remains soluble for no more than a few minutes in aerated solutions of $\mathrm{pH} 7.0$ or higher (McBride 1994). This does not imply that Fe is always soluble when soil $\mathrm{pH}$ is below 7.0. The dominant plantavailable form of $\mathrm{Fe}$ in soils is ferrous $\mathrm{Fe}\left(\mathrm{Fe}^{2+}\right)$; because $\mathrm{Fe}^{2+}$ reacts directly with oxygen $\left(\mathrm{O}_{2}\right)$ in an aerated soil solution, little, if any, soluble Fe will be available for turfgrass uptake until the soil $\mathrm{pH}$ falls below 4.0. Low soil temperatures may limit Fe uptake by reducing phytosiderophore production or by increasing bicarbonate accumulation, which precipitates soluble $\mathrm{Fe}$ as $\mathrm{FeCO}_{3}$. Humic and fulvic acids found in soil organic matter may increase Fe solubility. In short, $\mathrm{Fe}$ acts as a catalyst for the oxidation of organic matter by $\mathrm{O}_{2}$, which increases the amount of $\mathrm{Fe}^{2+}$ in soil solution. This reaction occurs despite the presence of $\mathrm{O}_{2}$ in soil solution; thus, Florida soils with appreciable organic matter should be less prone to producing Fe deficient turfgrass.

\section{Soil Testing for Iron}

Iron applications should not be based upon soil test Fe levels. Most soil testing labs will test for Fe, but do not provide a fertilizer recommendation. This is because the concentration of Fe changes rapidly in most aerated soils and, thus, by the time the applicator receives the recommendation, the soil Fe levels would likely be different from the initial soil concentration. In addition, soil test calibrations used to predict a response to the application of Fe have not been established on Florida soils.

\section{Iron Sources}

\section{Iron Sulfate}

Iron sulfate is perhaps the most common soluble granular Fe source for turfgrasses. Iron sulfate typically has an analysis of $20 \%$ Fe and appears as a white to light greenish-blue, angular particle or prill, and is $100 \%$ water soluble. Both granular and foliar forms of Fe sulfate are used in turfgrass management, but only foliar Fe sulfate has resulted in a positive turfgrass response in Florida. Granular Fe sulfate must dissolve into the soil solution and be taken up by the roots. During this process, Fe sulfate reacts with water to form an Fe hydroxide (Figure 2). This oxidation process is extremely rapid, resulting in as much as $95 \%$ of the applied Fe becoming unavailable within one hour of soil contact (Shaddox et al. 2016). In addition, if the oxidation process occurs on surfaces such as sidewalks, driveways, patios, etc., a reddish-brown stain will occur (Figure 3). Because these stains are formed chemically, they are difficult to remove. Therefore, Fe sulfate should be applied as a liquid to the turfgrass foliage rather than applied to the soil.

\section{Applied
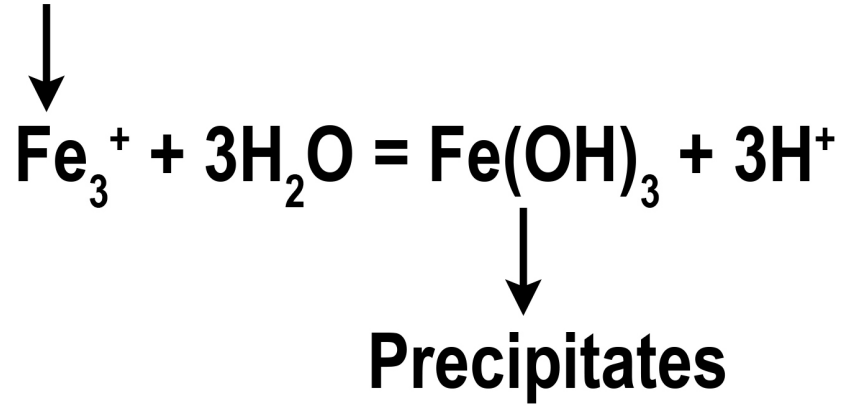

Figure 2. Iron applied to soil rapidly oxidizes and becomes unavailable for plant uptake.

Credits: Travis Shaddox, UF/IFAS

If applied as a foliar spray at $1-5$ pounds of $\mathrm{Fe}$ per acre, $\mathrm{Fe}$ sulfate generally improves turfgrass color for up to 4 weeks. The longevity of response is a function of the amount of Fe applied, the amount of $\mathrm{N}$ applied, and the time of year. Exceeding 5 pounds of Fe per acre increases the probability of leaf burn and may temporarily turn the turfgrass leaves black. Foliar Fe cannot be used to cure chlorosis resulting from $\mathrm{N}$ deficiency. Iron cures Fe deficiency and $\mathrm{N}$ cures $\mathrm{N}$ deficiency. 


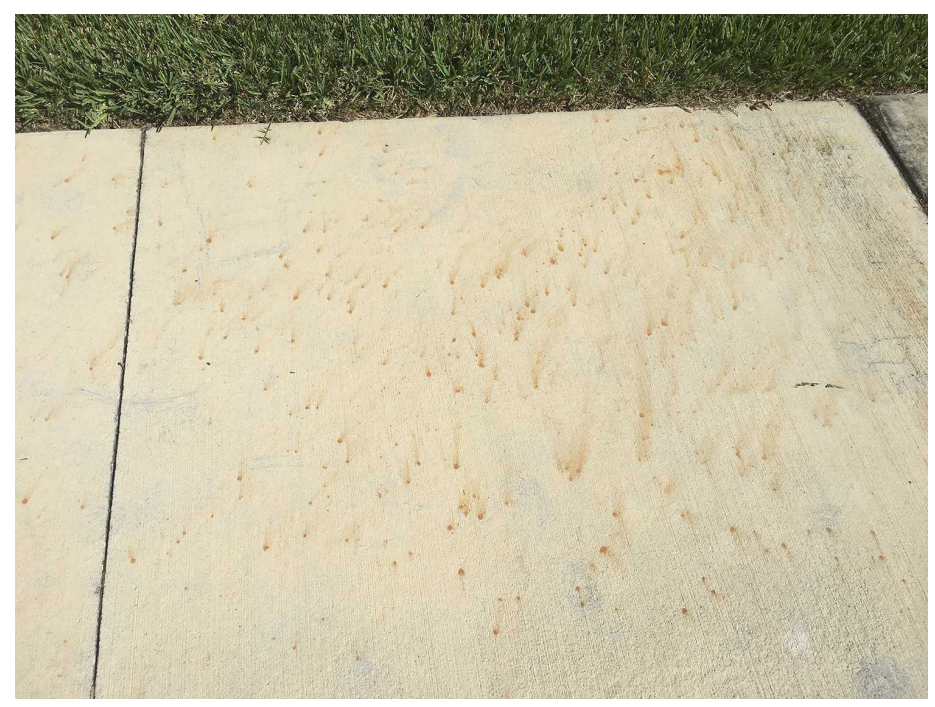

Figure 3. Fe sulfate fertilizer particles will rapidly dissolve and stain wet surfaces like this sidewalk in Gainesville.

Credits: Travis Shaddox, UF/IFAS

\section{Iron Humate}

Iron humate is the by-product of water treatment facilities that produce potable water from humate-rich river water (Rehberg and Smith 1997). The material is normally a dark brown-to-black granule and has a guaranteed Fe analysis of $14 \%$. Iron humate is approximately $30 \%$ water soluble, with the remaining Fe being in a slowly available form. Over a two-year period in two Florida locations, a single application of Fe humate at the rate of 20 pounds of Fe per acre resulted in no improvement in bermudagrass color or quality. Although a portion of the Fe is slowly available, the Fe must still solubilize into the soil solution before plant uptake can occur. Because the Fe is not chelated, the Fe entering the soil solution will oxidize similar to Fe sulfate.

\section{Iron Oxide}

Iron oxide is the end-product of Fe weathering, and more than $99.5 \%$ of Fe within Fe oxide is water insoluble. The product is normally a black, angular, very hard granule and guarantees $50 \%$ or more Fe. No turfgrass response to Fe oxide has been observed in research studies. Iron oxide and all forms of Fe oxide should not be used as a turfgrass fertilizer

\section{Iron Sucrate}

Iron sucrate is manufactured by pelletizing powdered $\mathrm{Fe}$ oxide using a sugar, usually molasses. The product is normally a spherical, black prill and guarantees $50 \%$ or more Fe. Although the prills readily disperse in water, Fe sucrate is not water soluble. The dispersion forms a suspension in water, but the fine particles remain insoluble. Turfgrass research using Fe sucrate clearly shows that Fe sucrate does not improve turf quality, growth, or color.

\section{Iron Chelates}

Chelation is the process of making an insoluble metal soluble by surrounding the molecule with an organic complex. Many Fe chelates exist for use on turfgrasses, but only ethylenediaminetetraacetic acid (EDTA), diethylenetriaminepentaacetic acid (DTPA), and ethylenediaminedi$o$-hydroxyphenylacetic acid (EDDHA) are documented to result in turfgrass responses when applied to the soil. EDTA, DTPA, and EDDHA may also be applied as a foliar spray, and the common guaranteed analyses range between $5 \%$ and $10 \% \mathrm{Fe}$. A relatively new chelate to the turf market is $\mathrm{N}$-(1,2-Dicarboxyethyl)-D,L-aspartic acid (IDHA). After one day of soil contact, IDHA resulted in an increase in soluble Fe in Florida soils compared to Fe sulfate (Figure 4), but the influence IDHA has on turfgrass color has not been determined. Other Fe chelates such as gluconate, glucoheptonate, and citrate applied as foliar sprays commonly improve turf color, but they do not increase the availability of Fe in the soil (Shaddox et al. 2016). Keep in mind that high application rates of Fe chelates, especially Fe EDTA, can be phytotoxic to some landscape plants (Broschat and Moore 2004).

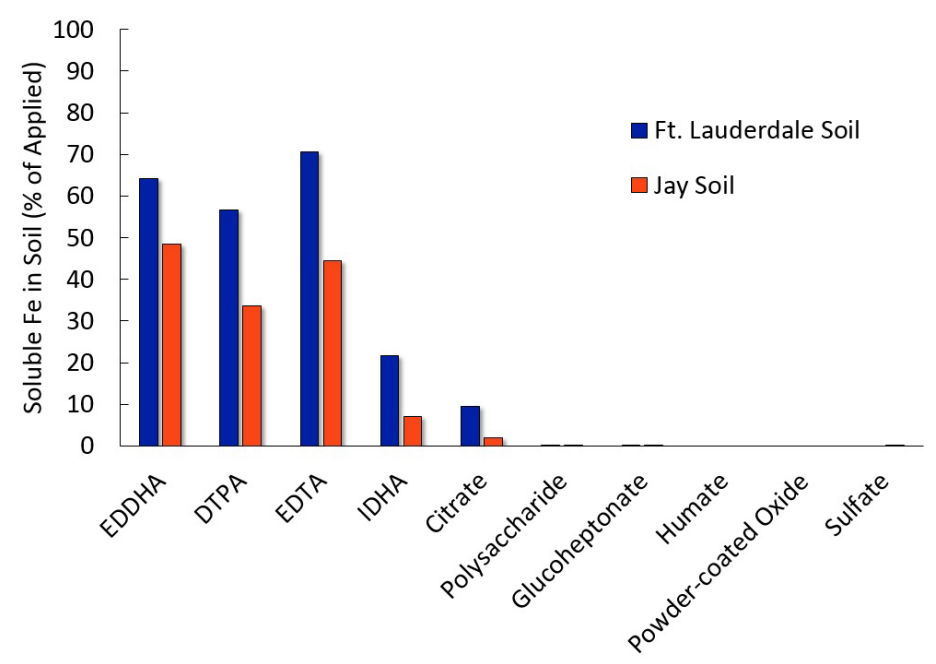

Figure 4. Solubility of Fe sources one day after application to Jay and Ft. Lauderdale, Florida soils.

Credits: Travis Shaddox, UF/IFAS

\section{Powder-Coated Iron}

Some fertilizers may be blended with a component of very fine Fe powder added when the fertilizer is being blended. This powder attaches to each fertilizer particle, which greatly increases the uniformity of Fe distributed across the turfgrass. The Fe powder may be derived from Fe sulfate, Fe oxide, or Fe chelate. Each of these powder-coated Fe sources have been tested on Florida turfgrass and none have increased turfgrass color or quality compared with untreated turfgrass. In the case of Fe sulfate and Fe oxide, the lack of response is due to the same soil chemical reactions 
that limit Fe solubility from conventional Fe fertilizers. In the case of powder-coated Fe chelates, the reason no response has been observed is unknown. However, it is likely that the amount of $\mathrm{Fe}$ chelate required to induce a response is greater than the amount of Fe chelate that can be applied via this coating method. Until a turfgrass response to powder-coated Fe is confirmed in Florida, the use of powder-coated $\mathrm{Fe}$ is not an evidence-based practice.

\section{Organic Iron}

The value of organic Fe in fertilizers (such as Milorganite ${ }^{\bullet}$ or municipal biosolids) is difficult to evaluate because most organic Fe sources also contain $\mathrm{N}$ and/or phosphorus (P). Separating the influence of $\mathrm{Fe}$ from the influence of $\mathrm{N}$ and $\mathrm{P}$ is very difficult and, thus, a bonafide response to organic $\mathrm{Fe}$ has not yet been documented on Florida turfgrasses.

\section{Summary}

Iron is an important component of any turfgrass fertility program and can enhance turfgrass quality and color. Granular Fe sources should be limited to EDTA, DTPA, or EDDHA, whereas foliar applications can include soluble Fe sulfate or chelates.

\section{References}

Broschat, T.K. and K.K. Moore. 2004. "Phytotoxicity of several iron fertilizers and their effects on $\mathrm{Fe}, \mathrm{Mn}, \mathrm{Zn}, \mathrm{Cu}$, and $\mathrm{P}$ content of African marigolds and zonal geraniums." Hortscience 39: 595-598.

Carrow, R.N., D.V. Waddington, and P.E. Rieke. 2001. Turfgrass soil fertility and chemical problems: assessment and management. Chelsea, Michigan: Ann Arbor Press.

Havlin, J.L., J.D. Beaton, S.L. Tisdale, and W.L. Nelson. 1999. Soil fertility and fertilizers: an introduction to nutrient management. 6th ed. Upper Saddle River, New Jersey:

Prentice Hall.

McBride, M.B. 1994. Environmental chemistry of soils. New York: Oxford University Press.

Rehberg, B.E. and G.L. Smith. 1997. "Iron humate production, processing, properties, and usage. Agricultural uses of by-products and wastes." American Chemical Society. 268-275.

Salisbury, F.B. and C.W. Ross. 1992. Plant physiology. 4th ed. Belmont, California: Wadsworth Pub. Co.
Shaddox, T.W., J.B. Unruh, J.K. Kruse, and N.G. Restuccia. 2016. "Solubility of iron, manganese, and magnesium sulfates and glucoheptonates in two alkaline soils." Soil Sci. Soc. Am. J. 80: 765-770. doi:10.2136/sssaj2015.10.0382. 